\title{
Nossos ossos, o quebra-cabeça ou primeiro romance de Marcelino Freire
}

Tatiane Pereira de Santana Ivo ${ }^{1}$

$[\ldots]$

Um no entanto se descobriu num gesto largo e demorado Olhando o esquife longamente Este sabia que a vida é uma agitação feroz e sem finalidade

Que a vida é traição

E saudava a matéria que passava Liberta para sempre da alma extinta. "Momento num café", Manuel Bandeira

O escritor Raimundo Carrero afirmou que a aposta de João Alexandre Barbosa no seu conterrâneo Marcelino Freire não foi em vão ${ }^{2}$. O crítico e professor de literatura escreveu o prefácio do primeiro livro de contos de Freire, Angu de sangue, destacando na escrita desse autor pernambucano as marcas da oralidade e a presença de narradores que experienciam o narrado.

Freire prosseguiu nessa toada e tem sido cada vez mais lido, reconhecido, premiado, inclusive porque sua atuação não se dá apenas como escritor, mas também como agitador cultural. Há quem não goste de suas narrativas, mas impossível passar ileso pela sua prosa poética, que, no mínimo, incomoda.

Após Angu de Sangue (2000) vieram mais quatro livros de contos, entre eles o premiado Contos Negreiros (2005), vencedor do Prêmio Jabuti em 2006, e o primeiro romance, Nossos ossos, publicado no final de 2013 pela Editora Record, com o qual o escritor ganhou o prêmio Machado de Assis 2014 de Melhor Romance pela Biblioteca Nacional. A obra foi traduzida para o espanhol e para o francês.

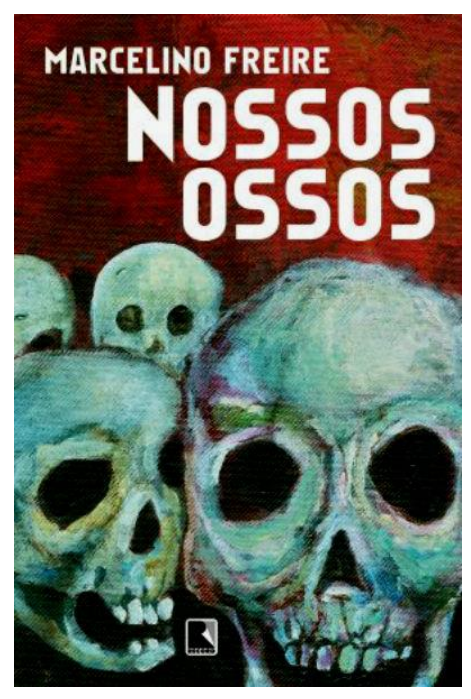

Esse primeiro romance ou "prosa longa", como o autor prefere denominar, descreve um dolorido percurso sentimental, marcado por amores, dores, perdas e saudades de um retirante nordestino ao chegar na "dura poesia concreta" das esquinas paulistanas. Trata-se principalmente de uma história sobre a morte, seja ela metafórica ou

\footnotetext{
${ }^{1}$ Mestranda pelo Programa de Estudos Comparados de Literaturas de Língua Portuguesa - FFLCH/USP. ${ }^{2}$ CARRERO, Raimundo. Nossos ossos agora estão nus e expostos. In: Suplemento Cultural do Diário Oficial do Estado de Pernambuco, n. 95, p. 9, jan. 2014. Disponível em:

<http://www.suplementopernambuco.com.br/images/pdf/PE_95_web.pdf>. Acessado em: 14 dez. 2015.
}

Revista Crioula USP, $\mathrm{n}^{\circ}$ 17, junho de 2016 
literal (o título e a capa, com ilustração de Lourenço Mutarelli, já prenunciam essa temática). Nesse sentido, é um texto triste, intenso e que, aparentemente, traz algum viés autobiográfico ou “autopornográfico", segundo palavras do próprio Marcelino Freire ${ }^{3}$.

Em Nossos ossos, imediatamente nos chama atenção a orelha do livro. Nela, diferente do que ocorre em muitas obras, não encontramos uma mera sinopse anônima ou um comentário feito por um crítico ou escritor importante. A orelha desse romance traz a assinatura do próprio narrador-protagonista, Heleno de Gusmão, em depoimento a Paulo Lins. E mais: nesse seu depoimento, Heleno se reconhece como ser ficcional e inventado por Marcelino Freire. Como pode um ser fictício depor para um sujeito real? O autor de Cidade de Deus também se tornaria um ser ficcional?

\footnotetext{
Meu nome é Heleno. Sou dramaturgo, protagonista deste prosa longa, primeiro romance de Marcelino Freire, e tenho um corpo morto de um michê para entregar ao seu pai e à sua mãe, mas não sei quem são e nem onde estão. [...] E aí vêm meu amor pelo boy, Lourenço me levando para ser "enterrado no coração de meu pai", o carinho por Picasso [...], o cara do táxi no ir-e-vir dessa narrativa que Freire inventou.

$[\ldots]$

Heleno de Gusmão, em depoimento ditado para

Paulo Lins (grifos nossos)
}

Se por um lado, como apontamos acima, parece haver uma ficcionalização da verdade, por outro, muitas vezes Heleno afirma a veracidade de sua história, ocorrendo uma espécie de "verdadeirização" do ficcional, como é possível observar na finalização do capítulo "As cavidades":

[...] pensei que, seu eu tivesse que escrever, na vida, uma outra peça de teatro, escreveria esta, a de um dramaturgo de sucesso que atravessa o Brasil em um carro funerário, levando, para seu último descanso, o corpo de um garoto de programa com quem ele havia trepado, uma história, digamos, de amizade, ao que parece, também daria um bom filme essa viagem, se não fosse ela, em vez de ficção, a mais pura verdade. (FREIRE, p. 76, grifos nossos)

No que concerne à forma, em Nossos ossos ecoam a economia e a concisão amiúde encontradas nos contos de Freire. O romance é composto por 34 breves capítulos - 22 na "Parte Um" e 12 na "Parte Outro" (cabe ressaltar aqui a ambiguidade do termo "Parte", que funciona tanto como substantivo quanto como verbo) - distribuídos em apenas 120

\footnotetext{
${ }^{3}$ Ver FREIRE, Marcelino. Um livro autopornográfico. Disponível em: <https://marcelinofreire.wordpress.com/2013/10/29/um-livro-autopornografico/>. Acesso em: $14 \mathrm{dez}$. 2015 .
}

Revista Crioula USP, $\mathrm{n}^{\mathrm{o}}$ 17, junho de 2016 
páginas. São reiteradas também, como apontamos no início desta resenha, as marcas da oralidade e a presença de personagens historicamente condenadas ao silêncio.

$\mathrm{Na}$ escolha do narrador, por exemplo, Marcelino Freire direciona os holofotes da história para uma voz que se inscreve no que Jaime Ginzburg chama de "narradores descentrados", uma voz que foge do centro, no qual estão inseridos agentes sociais que se identificam com "a política conservadora, a cultura patriarcal, o autoritarismo de Estado, a repressão continuada, a defesa de ideologias voltadas para o machismo, o racismo, a pureza étnica, a heteronormatividade, a desigualdade econômica, entre outros".

Embora Heleno de Gusmão seja um dramaturgo renomado, reconhecido inclusive internacionalmente, o que aparentemente o excluiria da marginalidade no qual se inscrevem muitos dos personagens de Freire, é homossexual e um imigrante nordestino que, como tantos outros, veio para São Paulo tentar a sorte. Esse narrador pertence, portanto, a dois grupos historicamente oprimidos e reprimidos. Destaca-se que circulam também pela narrativa outros nordestinos, outros homossexuais, michês e o centro paulistano, que, bem sabemos, é um tópos quando o assunto são as franjas da sociedade.

Heleno migra para São Paulo não apenas na tentativa-alcançada-de se consolidar profissionalmente, mas para reencontrar seu grande amor, o também pernambucano Carlos, por quem é ignorado ao chegar na cidade. Nela, o dramaturgo relaciona-se com garotos de programa, entre eles Cícero, o "boy" agredido e morto na Estação da Luz. É em meio ao processo de "localizar os pais de Cícero e resolver a transferência do corpo" para a cidade de origem, a fim de dar-lhe um fim digno, que o protagonista vai rememorando sua vida e caminhando para "dormir, dormir, dormir, nunca mais sofrer" (FREIRE, 2013, p. 52).

Sendo essa "prosa-longa" relato do presente e também rememoração, esta última reverbera na estrutura do texto. A memória é um trajeto de idas e vindas e assim é Nossos ossos: os capítulos, que em sua maioria recebem nomes de partes do corpo, alternam-se entre relatos do presente e lembranças do passado, não havendo uma cronologia que se segue a cada um deles.

À moda dos relatos épicos, o protagonista inicia sua narração in media res, isto é, em plena ação. No primeiro capítulo, “Os ligamentos”, Heleno já está na sua agência bancária para retirar todo o dinheiro que tem. O motivo pelo qual ele está fazendo isso providenciar o transporte do corpo de Cícero - saberemos nos capítulos seguintes. Diante disso, cabe observar que uma das estratégias para "ganhar" o leitor nessa história é o 
suspense. A cada capítulo vamos montando, tal qual um esqueleto ou um quebra-cabeça, o corpo dessa história - que constitui o passado e o presente desse narrador-personagem.

Nossos ossos é um texto permeado pelos silêncios, e nisso essa obra se afasta dos contos freirianos, enérgicos, gritantes e gritados. Mas assim como nos contos, cada palavra, repleta de significados, parece estar em seu devido lugar.

Por fim, cabe ressaltar que esse romance se afasta também do modo clichê de findar histórias. Tal qual uma peça de teatro, a tragédia do dramaturgo é finalizada não com um "fim", mas com um "Cai o pano": essa é a frase que encerra o livro. Seria Nossos ossos mais uma peça escrita e, nesse caso, encenada por Heleno de Gusmão? Quem parte? No que resulta a junção dessas partes? Seria Heleno uma espécie de Brás Cubas, um defunto-autor? Nossos ossos esperam vossos olhos.

\section{REFERÊNCIAS}

BANDEIRA, Manuel. Antologia Poética. 6.ed. São Paulo: Global, 2013, p. 149.

CARRERO, Raimundo. Nossos ossos agora estão nus e expostos. In: Suplemento Cultural do Diário Oficial do Estado de Pernambuco, n. 95, p. 9, jan. 2014. Disponível em: $\quad<\mathrm{http}: / / \mathrm{www}$. suplementopernambuco.com.br/images/pdf/PE_95_web.pdf >. Acessado em: 14 dez. 2015.

FREIRE, Marcelino. Nossos ossos. São Paulo: Record, 2013.

GINZBURG, Jaime. O narrador na literatura brasileira contemporânea. In: Tintas. Quaderni di Letterature Iberiche e Iberoamericane, n. 2, p. 199-221, 2012. Disponível em: <http://riviste.unimi.it/index.php/tintas/article/view/2790>. Acessado em: 2 dez. 2015. 